\title{
Компания Tabor Electronics - эффективные решения для работы с различными сигналами
}

\author{
Рассказывает менеджер по международным продажам
} компании Tabor Electronics Ш. Кацав

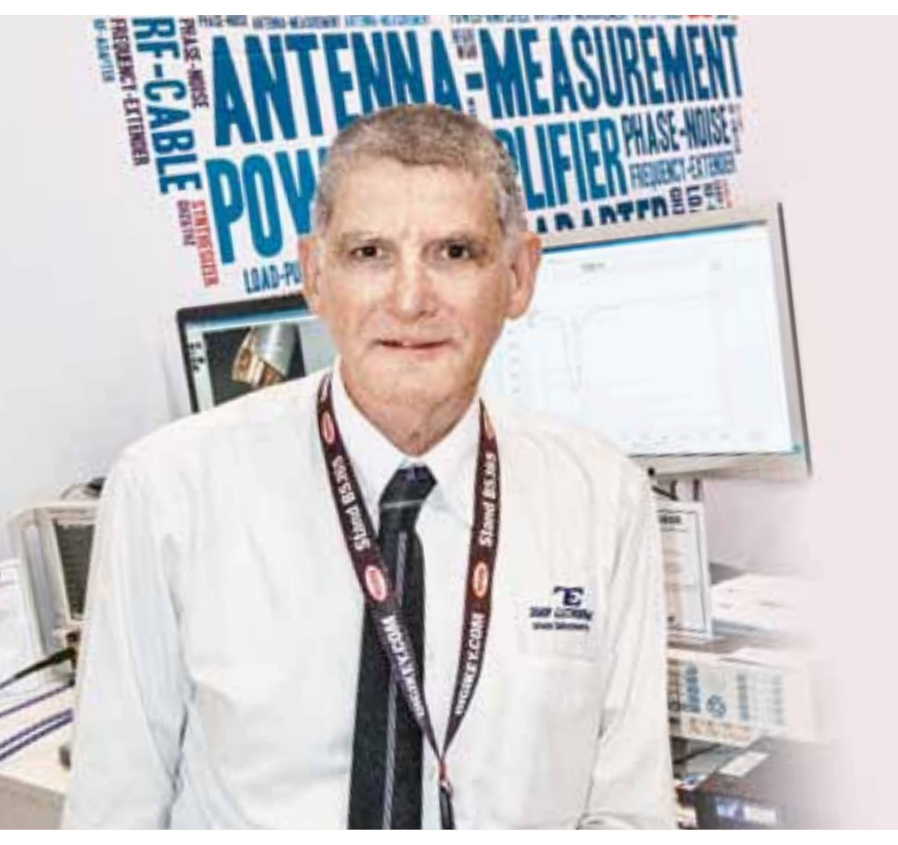

Компания Tabor Electronics (www.taborelec.com) была основана в 1971 году. Это частная компания, находящаяся в семейном владении. Tabor выпускает различные контрольно-измерительные приборы. В первую очередь это функциональные генераторы сигналов и генераторы сигналов произвольной формы. В линейке приборов каждого из этих типов представлены модели с разным числом каналов и различными диапазонами рабочих частот. Tabor производит также импульсные генераторы, усилители сигналов и ряд других приборов. Благодаря высоким техническим характеристикам, надежности и ценовой конкурентоспособности продукция компании Tabor находит применение в широком спектре приложений. За последние 10 лет Tabor существенно расширил географию поставок своего оборудования и сегодня имеет дистрибьюторов во многих странах в разных частях мира.

Помимо того, что компания сама является ведущим игроком на рынке генераторов сигналов, она уже давно выступает в качестве ОЕМ-партнера других известных производителей контрольно-измерительной аппаратуры. Tabor разрабатывает и производит продукцию для таких компаний как Fluke, Astronics Test Systems, Applied Materials и др.
Компания Tabor Electronics (Израиль) известный производитель контрольноизмерительного оборудования. В модельном ряду Tabor представлены приборы различного типа и класса. Продукция компании поставляется множеству клиентов в разных странах. Приборы Tabor успешно конкурируют с аналогичными устройствами других, в том числе более крупных производителей. На выставке electronica 2018 в Мюнхене (Германия) менеджер по международным продажам компании Tabor Electronics Шимон Кацав (Shimon Katzav) рассказал нам о продукции и направлениях деятельности компании.
Недавно мы выпустили новый для нас вид продуктов: аналоговые генераторы рЧ-сигналов. Данные приборы представлены на нашем стенде на выставке electronica 2018. Серия этих генераторов (Lucid Series) coстоит из трех одноканальных моделей с диапазоном рабочих частот от 100 кГц до 3, 6 или 12 ГГц. Приборы отличаются очень малыми значениями фазового шума (в одной боковой полосе, SSB): -145 дБн / Гц на частоте 100 МГц при отстройке 10 кГц и -132 дБн/Гц на частоте 1 ГГц при отстройке 10 кГц. Они оснащены интерфейсами SPI и micro-USB. Приборами можно управлять дистанционно из MATLAB, Python, LabVIEW и других программных сред. Предусмотрена возможность синхронизации нескольких генераторов. Приборы имеют малые для устройств такого типа размеры $(12 \times 16 \times 2,5$ см). Характеристики генераторов серии Lucid позволят успешно использовать их в широком спектре современных приложений.

На выставке electronica 2018 мы представили также решение для беспроводной технологии 5G, обеспечивающее генерацию сигналов с частотой 154 ГГц. Оно включает в себя генератор сигналов произвольной формы (модель SE5082), новый генератор рч-сигналов, а также усилитель, повышающий преобразователь частоты 
и др. Данное решение может также использоваться в радарах различных типов - военных, метеорологических, автомобильных - и в ряде других приложений.

Наши разработчики постоянно активно занимаются созданием новых поколений приборов. Мы все время поддерживаем обратную связь с потребителями нашей продукции и учитываем их пожелания и замечания при создании нового оборудования. В ближайшие месяцы мы планируем представить очередное семейство новых продуктов.

Хотелось бы также сказать, что в последниепять-шесть лет компания Tabor активно развивает продажи своего оборудования образовательным учреждениям. Мы поставляем большое количество своих приборов разного типа и класса в университеты, работающие в области физики, в том числе квантовой, электрони-

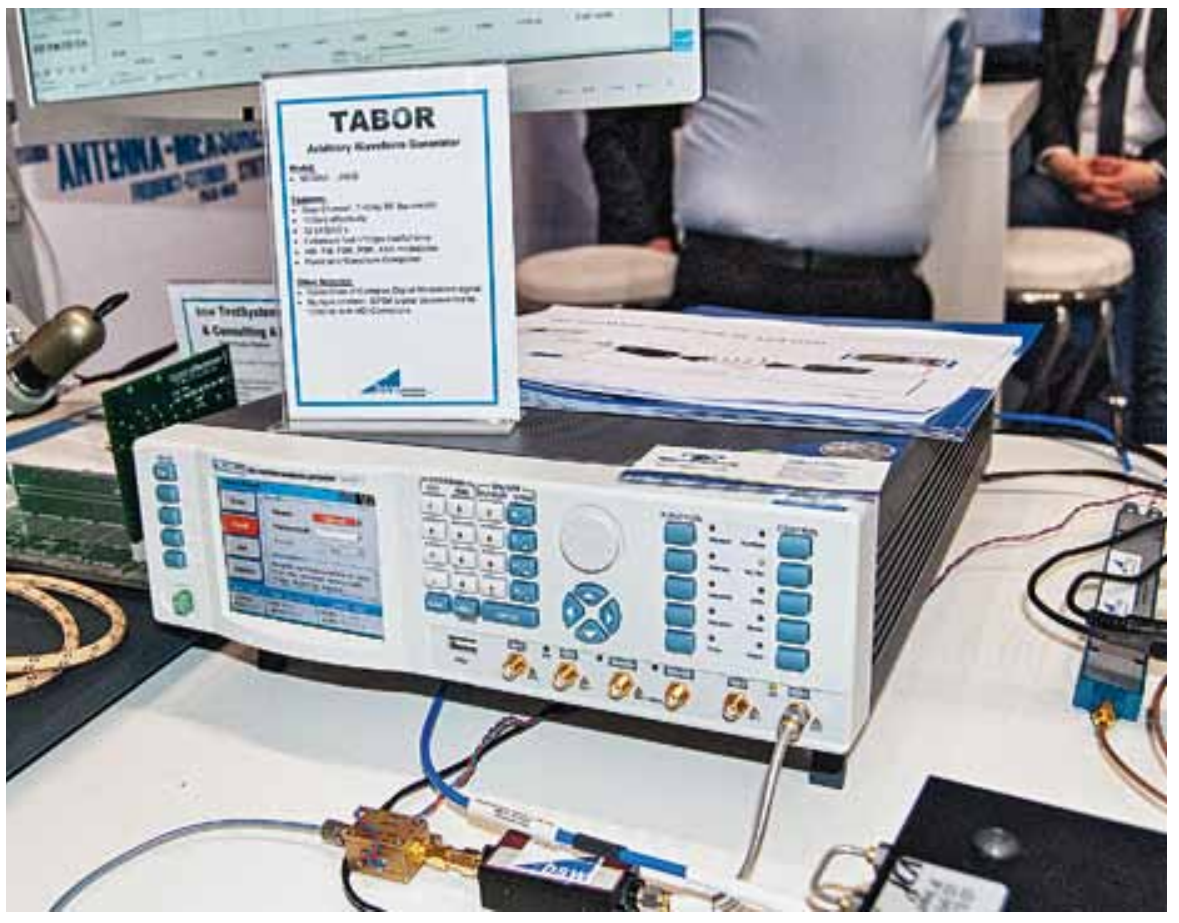

Генератор сигналов произвольной формы SE5082 ки, биотехнологий и др.

Важно отметить, что мы широко занимаемся доработкой нашего стандартного оборудования в соответствии с требованиями заказчиков. Мы готовы делать это, даже если речь идет об одном или двух экземплярах приборов, причем в большинстве случаев не берем за это дополнительных денег - главное, чтобы заказчики были удовлетворены.

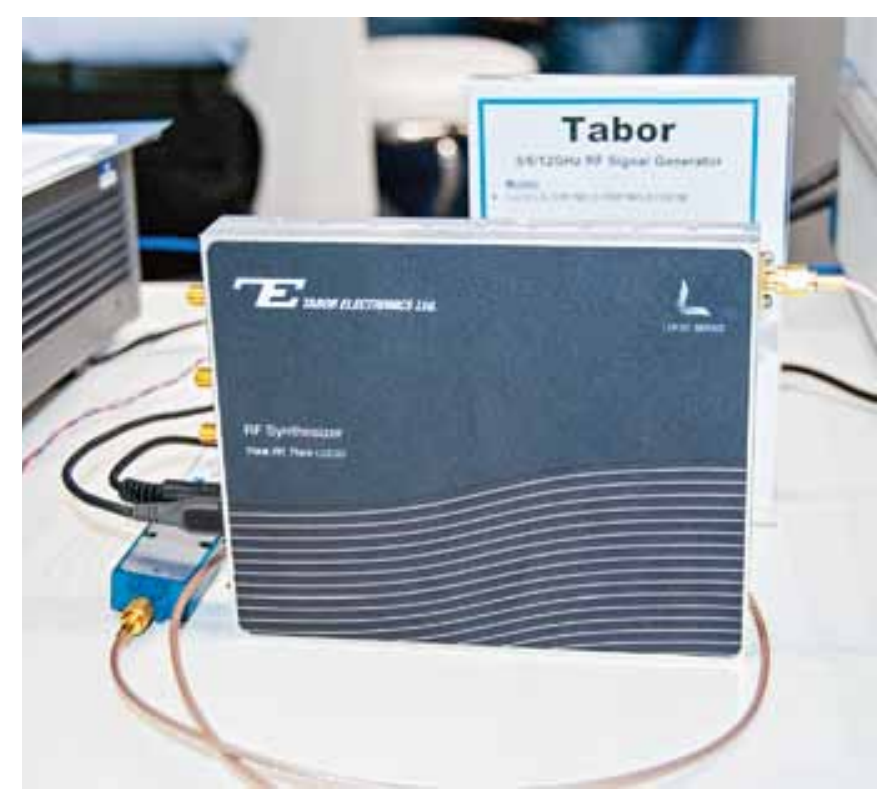

На российском рынке мы работаем уже много лет. Наш дистрибьютор в России - компания "ПриСТ», с которой у нас сложились очень хорошие партнерские отношения. Tabor продает много своих приборов в России как университетам, так и промышленным предприятиям. Мы надеемся, что за счет новых продуктов, которые уже выпущены или появятся в скором времени, нам удастся существенно расширить свои поставки в Россию, поскольку мы знаем, что в России есть рынок высокотехнологичной продукции. Российский рынокодин из тех, где наш дистрибьютор способен работать самостоятельно, без нашей поддержки, - как при продажах оборудования, так и при его техническом обслуживании. Таким образом, мы рассчитываем на рост объемов наших поставок в Россию в 2019 году по сравнению с 2018 и 2017 годами.

Конечно, в России, как и в других странах, мы вынуждены конкурировать с крупными производителями контрольно-измерительного оборудования, такими как Keysight Technologies или Tektronix. Эти фирмы более широко известны, но наши клиенты знают, что, работая с компанией Tabor, они всегда могут рассчитывать на высокое качество оборудования, его долговременную гарантийную и техническую поддержку - как со стороны фирмы «ПриСТ», так и с нашей. Поэтому они возвращаются к нам снова и снова, большинство наших клиентов это те, кто уже приобретал продукцию компании Tabor и убедился в ее преимуществах.

Mатериал подготовлен Н. Елисеевым 